\title{
Quality video lectures: high professional competence and good acting skills
}

\author{
Veniamin Norin ${ }^{1 *}$, Natalia Norina $^{2}$, and Yurii Pukharenko ${ }^{1}$ \\ ${ }^{1}$ Saint Petersburg State University of Architecture and Civil Engineering, Department of Technology \\ of Construction Materials and Metrology, Vtoraja Krasnoarmejskaja ul. 4, St. Petersburg, 190005, \\ Russia \\ ${ }^{2}$ Saint Petersburg State University of Architecture and Civil Engineering, Department of Construction \\ Mechanics, Vtoraja Krasnoarmejskaja ul.4, St. Petersburg, 190005, Russia
}

\begin{abstract}
Currently we see actively developing systems associated with distance learning, and such systems are based on new communication tools. They not only change the appearance of information space but also create special conditions for the formation of the modern distance learning system. The article describes requirements that must be established for an analyst teacher (a personality-technologist-analyst), whose training, in contrast to the training of a duty-holder teacher, comes to the fore, and who must be able to create technologies when adapting to new conditions of the constantly changing world, rather than to perform under pre-set technologies. The articles outline the substance of the creative method in teaching; it has been emphasized that teacher's activities are very close to those of an actor. Ways to resolve the issues of distance learning regarding acting as part of the teaching practice are outlined herein.
\end{abstract}

\section{Introduction}

At the stage of building the information society, the nowaday's advanced technologies particularly the Internet - make the integral part of the development of the communication environment. New electronic media (media) have emerged on the aforesaid base for the recent decade. They are gaining more and more importance and are expanding their target audience coverage. Concurrently we see the continuing development of systems associated with distance learning, and such systems are based on new communication tools. They not only change the appearance of the information space but also create special conditions for the formation of the modern distance learning system.

Actually, the only means for conveying educational information in distance learning system are multimedia tools implemented within the scope of Internet technologies. Due to the fact that distance learning and multimedia tools as such are at the stage of continuing development, this area is the subject of the wide range of scientific research [1].

The tasks that comes to the fore is training of a person-technologist-analyst, who could create technologies in the process of adapting to new conditions of the constantly changing world, rather than a person- technologist-duty holder (a duty holder teacher), who is able to

* Corresponding author: norin.va@yandex.ru 
perform in line with the pre-established technologies (and inter alia, in line with information technologies) [2].

Multimedia tools used in the learning system are identical to the tools used in journalism. The difference is in their use. Just as educational television that was the subject of research in the last century, the current situation is featured by the concurrent research of multimedia in both education and mass communication contexts.

In modern scientific literature, the concept of "multimedia" has been the subject of indepth research as a new communicative and aesthetic phenomenon. Nevertheless, the use of multimedia in distance learning is almost left undescribed. The description of the multimedia tools actively used in the distant learning system is new and important for understanding the genre structure, its sociogenic nature, interactivity, and virtuality [2].

Analysis of the use of television and radio in education system has been performed in a number of works with varying degree of generalization and scientific interpretation [3].

The current status of the distance learning is described in the works referred to [4-8]. Therewith, the analysis of available scientific literature shows that the topic of "Multimedia tools in distance learning system" has been studied insufficiently [2, 9]. In addition to the aforesaid, the process of reinterpretation and conceptualization of the new tools within the scope of the developing multimedia is lagging behind the implementation of new information technologies, both in teaching practice, and in mass communication [10-12].

\section{On the creative method in teaching}

Currently educators, including scientists and those who educate young researchers, are clearly aware of the high responsibility vested on them in connection with the rapid development of new information technologies. In the course of implementation of online learning forms it is necessary to retain the educational effect produced on the learner, which, in its turn, consists of two components: on the one hand, a teacher can develop the intelligence of their audience in multiple ways, changing accordingly the teaching method; on the other hand, the pedagogical process as a whole makes a visible impression on the shaping personality of the student and his/her attitude to a given subject [13].

When talking about the impact produced by the teaching method on a student's intelligence, the following is implied.

A teacher, who teaches, for example, a STEM subject, can pursue various purposes: either he will confine to demand from his/her audience to firmly remember a number of formulas, and will take efforts to have the students to obtain the formal knowledge of equations, theorems, etc.; or he may want the students to first of all understand the content of the material; or a teacher might seek to awaken and develop in the students the appropriate ability and taste for independent thinking. From our point of view, teaching should be aimed at to not only teach students a given subject but primarily develop their thinking. The main features of thinking are as follows:

- The ability to get an insight into the substance of the phenomenon under study

- The ability to generalize and to expand concepts

- The ability to think in analogies and to model

With the aim to have the students developing the aforesaid aspects of thinking, it is required to introduce elements of philosophy of a particular science, elements of its history, biographical information about big scientists, who worked in a given subject. Elements of historism should be introduced into a subject in the following three directions:

- "We need to make it possible for students, - a big authority Paul Painleve said, - to touch to the very beginnings of experimental methods and to those most skilled techniques invented by great inventors, - techniques and methods, highly specific and much more persuasive and fruitful than all the theorems and rules". 
- Widespread use of the richest historical material in lectures. For example, the story of every engineering science is very rich in examples, emphasizing its importance for the development of state military power and technology in general. Such examples can certainly significantly increase the students ' interest in studying their subject.

- Inclusion of biographical information about creators of science into lectures. Pedagogical experience shows that a vivid, bright display of images of such luminaries of the global science, such as Galileo, Kepler, Le Verrier, and Lagrange, Coriolis, Arago, I. Bernoulli, etc., not only helps to unveil for students the methods and techniques of scientific research, but also to give the scientific pathos, the passion for science, which inspired those great scientists.

Creative method of teaching can largely affect the formation of students' attitude to science. Every teacher at any school (a secondary, special, higher one) is well aware that a learner's attitude to the subject, and hence to a science, may be different. A subject may cause hatred, loathing, others may experience dislike, indifference or interest, love, passion and finally obsession. In this case, the whole responsibility almost exclusively is vested on the teacher, as, no doubt, every subject studied by a listener will be forever, for the whole associated in his/her mind with the person who taught him/her that subject.

The aforesaid significant role of the teacher imposes upon him/her a great responsibility and requires hard and continuing self-cultivation. A teacher should work hard to improve; for this purpose he/she needs to learn continuously not only the subject, its history and philosophy, but also must improve his/her teaching technique. In this respect, the activity of a teacher is very similar to that of the actor.

Thus, proceeding from the aforesaid excursus into the history of the development of teachings staff training, it is possible to draw the following conclusion: a success for online learning, both as for the traditional forms of learning, can be guaranteed exclusively when both forms are based upon time-proven facts and techniques. Staging of a lecture in the first case is a much more complex and specific process. Students sitting in front of the monitor, must feel that the lecturer "is performing a lecture" together with them rather than in front of them. A virtual lecturer must be so much convincing that the audience could not have any doubts about his sincerity and competence. A virtual lecturer, when presenting a wellknown material repeatedly, must each time so to speak relive emotionally the whole freshness and novelty of the first perception of such material. Learners must see a teacher loving his subject, his work, his audience and burning alive in the flame of scientific passion in front of them.

It should be noted that there are issues in today's distance learning, which are associated with insufficient quality of various video lectures.

Quality and efficiency aspects of e-teaching have virtually not been discussed yet despite of many research papers dedicated to forms, types, and opportunities of using eteaching technologies, which describe their technical constituent in full and justify economic expediency to apply them. In practice, we most often deal with a huge range of educational video products that may be found online, including those with free access. Hence, 562 thousand search results were found on Youtube by keyword "video lecture", 53,900 search results - by keyword "educational video lecture", and 12,400 search results by keyword "video lecture for learning". At the same time, the data is being updated constantly. However, the increase in number of educational video products and everdeveloping technological advance in learning do not solve the quality issue remaining debatable regarding the lecturer's role in the arrangement of modern teaching process. Should a lecturer be the primary subject in the teaching segment? Lazarenko [14] showed the lecturer's personal presence was needed regardless of a teaching model (be it classroom or distance learning). It was found that students used their arbitrary attention and actively 
memorized polysensory information in this case. However, what merits should the lecturer feature under modern conditions?

A lecturer-actor capable to captivate the students' interest with his/her subject is a rarity. While the role, function, requirements, and professionalism of lecturers have been thoroughly studied, there are virtually little or no papers that study the acting component of the lecturer's skills when preparing a digital video lecture for distance learning.

The weakness of modern teaching process is traditional opinion, that lecturer is only a speaker or talker, but not an artist who can inspire the student auditorium.

\section{Methodology}

The primary issue of the research is how to improve the quality of distance learning. In distance learning, as students are unable to have a personal contact with the teacher and there is no live communication, development of high-quality video lectures is intended to compensate this disadvantage.

The study used the descriptive analysis approach to investigate the modern state of distance learning and to develop recommendations to improve quality of video lectures as the primary element of distance learning.

Moreover, the study also used an experiment to verify the effects of initial emotional state of students during a class on memorizing study materials.

\section{The current state of distance learning}

To analyze the state of things regarding remote lectures, the authors studied the data of Central Radio and Television Universities (CRTVU network) in China, India, Japan, USA, Russia, Australia and other countries.

National University Teleconference Network (NUTN) is a consortium incorporating 260 educational organizations, who offer the opportunity to learn via satellite communication facilities under more than 100 college programs.

The nowadays-advanced distance learning systems are designed on the base of web information technologies and multimedia tools, experience of traditional school, knowledge, and practices of educational.

Integration of television and Internet enables to expand creative capacities of advanced online learning systems.

Knowledge of regularities in presentation of information and accumulated development in the field of educational television are widely used in advanced online learning systems in Russia. Elements of digital television, which is integrated into a global network, are currently used as additional information and supporting materials covering in more detail a particular topic both in online learning and in traditional learning systems. For example, Academia television project initiated by the Russian Kultura TV channel and participated both by major scientists of today and young scientists who speak to a wide audience to attract attention to domestic science and to expand the circle of people interested in knowledge development.

A well-established practice is online communication of teachers and students, which makes the integral part of the online learning process. Within the scope of such communication, students can consult with teachers; discuss projects, solutions, and scores with them. This also enables the teachers to observe the progress of learning material digestion and to organize training sessions based on individual approach.

Asynchronous system of communication between a teacher and a student, which is required for exchange of information (questions, tips, additional material, tests), enables to 
analyse messages received and to respond to them at any convenient time. Currently the most popular form of asynchronous communications is represented by global telecommunications networks. The benefit of the use of global and national networks, such is Internet, is quite obvious. If a teacher and students reside in the same region and use the same server, it is not expedient to use a global network. In this case, it is much cheaper to set up a local electronic Bulletin Board System (BBS) based on PC-server. It is very easy to joint BBS: it is enough to call to the server and connect your PC with it via a modem. Thus, it is possible to use BBS for communication between teachers and students within a city.

Nevertheless, low level of information culture of older teachers is a large issue of distance learning in Russia. Apparently, they do not always have a possibility to master multiple multimedia tools. In our view, this occurs, on the one hand, due to the fact that such training requires additional resources (technical, time, financial), and, on the other hand, there are no multimedia applications for distance learning.

The authors have carefully reviewed the learning technologies used by Concordia University (prof. Saul Carliner), Hong Kong Polytechnical University (Prof. Patrik Lambe), University of Texas (Prof. Patricia McGee), University of Florida (prof. David Merrill), Brigham Young University, Hawaii, University of Utah, University of Maryland (Wayne Precht), University of Georgia (Thomas C. Reeves), University of Wollongong, Australia (prof. Jan Herrington), University of Edith Cowan, Western Australia (Prof. Ron Oliver) and others $[15,16]$.

Thus, in particular, at Massachusetts Institute of Technology (USA) for future programmers there has been developed an electronic resource providing for study of basic subjects (classical mechanics, mechanics of composite materials, mechanics of materials), including hands-on and practical laboratory tests. Lectures presented in the form of text material with pictures and diagrams, are accompanied by captions in several languages. Also at the same Massachusetts Institute of Technology (MIT) a real time online learning systems has proved to successful.

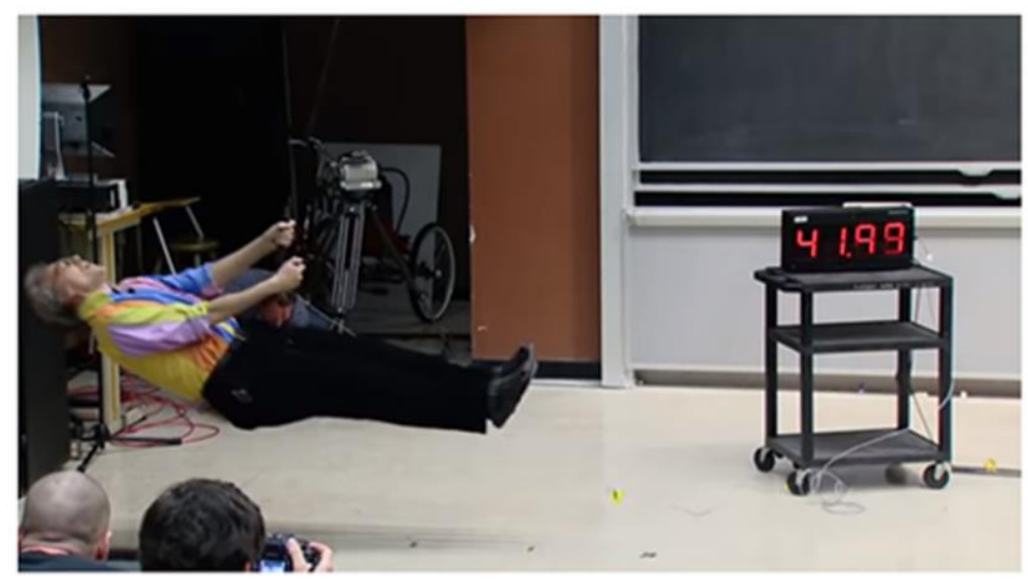

Fig. 1. Fragment of a lecture in Physics delivered by Prof. Walter Lewin (Source: https://www.youtube.com/results?search_query=Lewin+Walter $+\% 282017 \mathrm{c} \% 29 .+$ Hooke $\% 27 \mathrm{~s}+\mathrm{law}+\mathrm{a}$ nd+simple+harmonic + oscillation)

Video lectures of Walter Lewin, who was undoubtedly the best teacher of Physics worldwide were posted on MIT OpenCourseWare. Ninety-four lectures - three full courses plus seven separate lectures - are attended daily by about three thousand people, which means more than a million views per year. Among the listeners is even Bill Gates, who, according to him, has watched the entire course 8.01 in Classical Mechanics, 8.02 in 
Electricity and Magnetism, and is looking forward to watching the course 8.03 in Oscillations and Waves. Introducing audiences to the wonders of Physics, Walter Lewin is doing pure magic. Walter Levin is surprisingly charismatic and has the gift to capture attention of the audience; he is a real actor and is literally obsessed with Physics. This physicist-actor-teacher in the classroom is a genius and unrivaled inventor to provide simple explanations for complex ideas (Fig. 1).

He is the most vivid example of the "modern" Richard Feynman (Fig. 2): he is lively and energized, with a plenty of snap, he wants to captivate the audience on emotional level using a variety of tricks and gimmicks, rather than giving hands-on knowledge that is required in line with the curriculum.
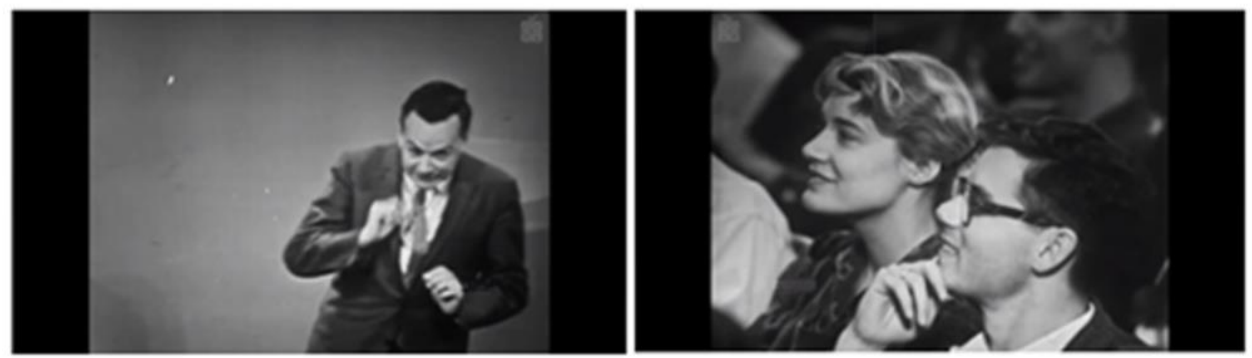

Fig. 2. Fragments of a lecture in Physics delivered by Prof. Richard Feynman (Source: https://www.youtube.com/watch?v=kekayfI8Ii8)

At Stanford University (USA) course of video lectures is used (prof. Brad Osgood) on electrical engineering and electromechanics. The lectures are accompanied by captions in Japanese, Spanish, and French.

Swedish scientists [17] noted in their studies that the number of students enrolled in real-time programs is steadily growing, while the number of students enrolled in the traditional form programs has declined substantially. Online video conferences are widely used at educational institutions of Sweden.

Proceeding from the analysis findings, we can highlight the following types of video lectures with qualitative features:

- an introductory lecture that includes an overview of the course key points and designation of the course objectives and goals;

- an overview lecture that makes it possible for the students to systematize scientific knowledge and provides them with the general course review, excluding details and narrow focus;

- a topic-focused lecture that is intended for consistent systematic presentation of the course contents over a longer time versus other types of lectures under review;

- a final lecture that integrates, generates, and shapes the knowledge obtained in the course of the learning process.

Therewith, according to the analysis findings, every teacher comprehends a new form of learning by trial and error.

Teachers like Walter Levin and Richard Feynman are very few nowadays. We must admit that such a gift from God is unique. Many university professors have excellent knowledge of the subject and are famous researchers. They are great at scientific activities, but they lack acting skills. This is largely due to the psychological type of scientists lecturing at technical universities. As a rule, those are introverts who are less focused on communication and multiple activities but are more comfortable to spend time alone reflecting on their inner world, anxieties, and feelings. Introverts may become good scientists, philosophers, writers, researchers, and travelers. Distinctive features of introverts are as follows: self-organizing ability, punctuality, modesty, prudence, thoughtfulness. An 
introvert is an alien to everything involving interaction with others; he is comfortable to work alone, relying solely on his own. Lack of communication skills becomes an issue for introverts. Such lecturers, when standing in front of the operating camera, are too static and tense. They lack the freedom of communication that usually exists between a lecturer and students in the classroom. In this case, the teacher lecturing from the monitor screen can often be called a commentator. Such teachers are unable to convey their thoughts and ideas to the mind of listeners and inspire them. Video courses of various subjects developed by such teachers, and they are the majority - cannot be considered a high-quality product. This may be a large issue if you want to improve the quality of distance learning.

\section{The role of acting in the development of online training courses}

It is a well-known fact that quality of the training process depends on the students' attitude to learning, which is a sum of motivational and emotional components [18]. Motivation stimulates certain types of behavior, primarily those enabling a person to achieve certain objectives. Emotions are referred to subjective experiences related to the process and result of the objective achieved. In this regard, quality of video lectures is the most important. Students' attitude to studying and whether they will remain faithful to the chosen occupation ultimately depends on what exciting and interesting way a video lector chooses to present the educational material.

Unfortunately, for the most part, the existing online training courses do not cause a strong emotional effect on students. The positive effect on the learning process caused by emotions has been a long-known fact; still, unfortunately, the overall situation has not changed. Meanwhile, emotions create motivation; they make it possible for the teacher to catch attention of listeners and make it easier for students to keep the material in memory. It is known that the process of digestion of knowledge and emotions are dynamically interrelated and interdependent in terms of neurology and psychology. Emotions and digestion of teaching material are not merely interrelated, but their interaction is necessary for adaptive learning. Increased emotional arousal associated with the training session affects the persistence of memorizing the session.

Many studies show that positive emotions can improve memory, long-term memory retention, and subsequent retrieval of information from memory [19]. When emotions are the basis of the experience gained in the learning process, this enables improvement of individual's ability to keep information in memory. Emotions improve digestion of information and make the learning process significant and memorable. When powerful visual images or situations involving emotional experiences make a part of the teaching and learning process, they can also improve memorization of the material [20]. Clear, meaningful memories will remain about an emotionally charged situation rather than a similar situation that is not associated with emotions. Apart from that, emotions often underlie curiosity and creativity, which can be motivating factors in learning.

In the process of gaining knowledge, students continuously assess what is happening around. The resulting emotional reactions may affect the learning process. For example, a student who is bored by a particular course may also feel unsatisfied and irritated. These feelings, in turn, may affect his or her attentiveness. A positive response to the learning process should help the student stay concentrated.

The studies conducted during the last three decades showed that emotions can influence many processes employed in learning [21]. However, a number of scientists deny memory dependence on the initial emotional state. For instance, Bower G.H. found no effects of mood on reproduction of emotionally positive and negative words, while other authors observed better reproduction of 'emotional' words without any differences in sign in people 
with instilled depression. Some authors note correlation of mood and type of word memorizing only in those participants who expected this result.

It should be noted that, over the last 20 years, the number of publications dedicated to emotional aspects of learning is rather small as compared to cognitive or motivation aspects. Insufficient study of emotions in the research of multimodal learning is expressed in limited use of some data [22]. It also has been noted that objective data that may specifically concern emotional aspects of learning are most often ignored. Therefore, future studies must use objective data to expand existing knowledge of emotional aspects of learning.

In this connection, the authors set up an experiment to confirm dependence of information memorizing on emotional state of students during a lecture.

Long-term experience in metrology teaching at a university shows that some materials of this discipline are poorly understood and memorized by students. For example, when teaching the Types of Measurement Scales, there is a problem to realize that summing and subtraction can be done with numerical values of the measured magnitude obtained under the interval scale, but multiplication and division is impossible.

Two units of $2^{\text {nd }}$ year students who were being lectured were randomly selected for the experiment, with four groups of students in each unit. The students had a similar level of training. The total number of participants of the study were 224 persons, with 114 in control groups and 110 in experimental groups. In all groups, lectures were given remotely at the Teams platform due to COVID-19 pandemics. When explaining study materials poorly understood and memorized by students in experimental groups, a funny story was told, which reflected the issue in a bright expressive form for understanding and memorizing. In control groups, this lecture was delivered in a usual manner. Lectures were delivered to students of experimental groups and control groups in February 2020.

At the semester end's examination taken place in June 2020 remotely as a test, students of experimental groups and control groups responded to the same test question related with the topic of Interval Scales. The results of students in experimental groups are represented in Table 1, while those for control groups are given in Table 2 and Figure 3.

Table 1. Results of students' answers in experimental groups.

\begin{tabular}{|c|c|c|c|}
\hline Groups & $\begin{array}{c}\text { Number of } \\
\text { students }\end{array}$ & $\begin{array}{c}\text { Number of students who gave } \\
\text { correct answers to a test question }\end{array}$ & Results as percentage \\
\hline 1 & 28 & 22 & 79 \\
\hline 2 & 25 & 23 & 92 \\
\hline 3 & 27 & 23 & 85 \\
\hline 4 & 30 & 27 & 90 \\
\hline
\end{tabular}

Table 2. Results of students' answers in control groups.

\begin{tabular}{|c|c|c|c|}
\hline Groups & $\begin{array}{c}\text { Number of } \\
\text { students }\end{array}$ & $\begin{array}{c}\text { Number of students who gave correct } \\
\text { answers to a test question }\end{array}$ & Results as percentage \\
\hline 1 & 26 & 4 & 15 \\
\hline 2 & 29 & 9 & 31 \\
\hline 3 & 30 & 5 & 17 \\
\hline 4 & 29 & 8 & 28 \\
\hline
\end{tabular}




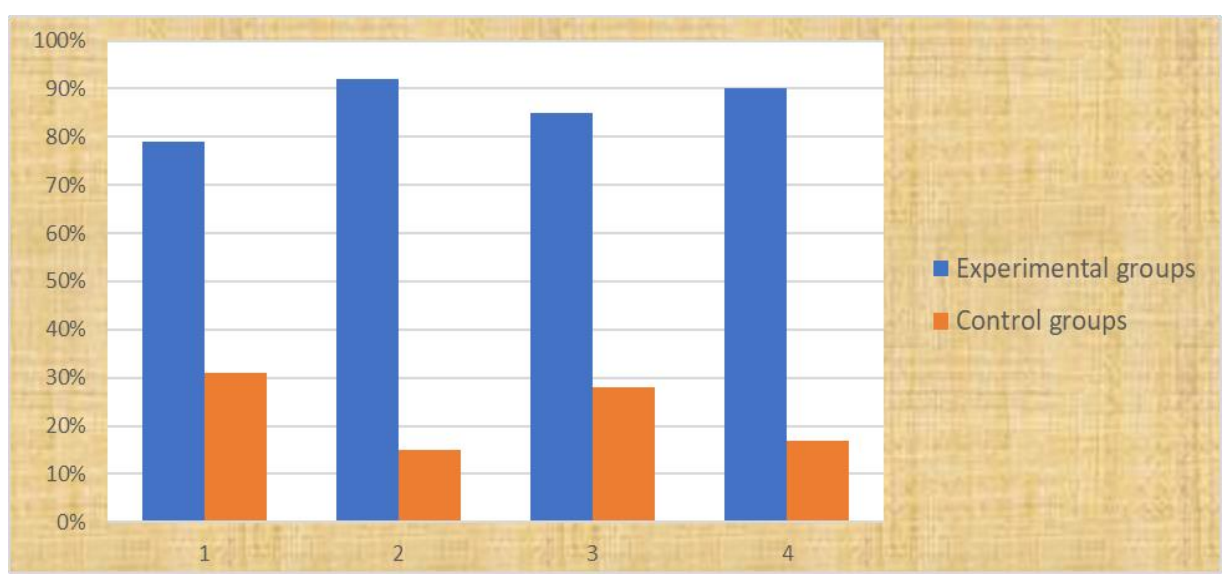

Fig. 3. Number of students who gave correct answers to a test question.

A percentage of correct answers in all experimental groups was much higher as compared with the results given in all control groups. To verify dependency of difference between experimental groups and control groups, a statistical analysis was completed for obtained experimental data using the Student t-test. Processing of experimental data gave the empirical Student t-test value of 5.92, and the critical value at significance point $\mathrm{q}=0.01$ was 3.71 , e. g. differences between experimental groups and control groups are statistically relevant and cannot be deemed random.

In this manner, this experiment proves that memorizing of study materials is much better if the students develop pronounced emotions towards its content when studying those materials. Students memorize and then reproduce the information that caused interest and emotion.

The analysis of the list of students who attended the lecture showed that students of experimental groups who failed to answer the test question did not attend the lecture in this topic. This makes us believe that if they were at the lecture, the percentage of correct answers would be higher.

It should be noted that the emotional component of the learning process is especially relevant because of adopting distance learning in higher education. In such conditions, the teacher should comply with new requirements that he/she is not used to. Video lectures, just as class lectures, must entice interest to the topic under study. This can be achieved by utilizing the emotional component of human psyche. Therefore, the teacher's role becomes more important because he/she must be an actor who is not afraid of a video camera and capable to capture the audience's attention using unique techniques.

But what should we do if a talented scientist who has something to say to students, lacks acting skills, is unable to captivate the students on the emotional level or get the audience interested? Landau, for example, was a very talented physicist with extensive knowledge, but he lacked the ability to present scientific results intelligibly and in plain language "for everybody to understand".

In this case, according to the authors, it would be possible to engage professional actors with distinct acting skills for video lectures. A researching professor could develop a script for a video lecture, and a professional actor would skillfully implement this script in front of the audience. This scheme is successfully used in advertising. Obviously, when recording such a video, the lecturer will have to sacrifice "feedback" from the students; an actor can only play the part offered to them, but they are not a carrier of knowledge. However, there is no "feedback" in TV and radio advertising as well, but this does not 
prevent the advertisers from having an extremely successful influence on viewers and listeners. Students may contact a professor to ask any questions about the video lecture.

In order to implement the planned ideas about what should be a remote lecture, the authors of the article made the first director's attempts at the Saint Petersburg State University of Architecture and Civil Engineering based on the case studies of teaching technical subjects. The results of the work are described in the article [23].

\section{Recommendations}

In the authors' view, it is possible to change and improve developing a new generation of video courses as follows:

1. When developing an online training course, it should be borne in mind that visual design of the course may enhance the emotional response of students. To develop a training course properly and to achieve meaningful results, an opportunity should be used to employ the features of human sensorial perception. The proper design of a training course can cause positive emotions and have a positive effect on ability of students to digest the material.

2. To develop a video course, we recommend using emotionally charged visual images. Images of people's facial expressions or expressive gestures evoke emotional response and are equally perceived by people of different cultural backgrounds. When it is acceptable in terms of the learning process, emotionally enhanced images may be effective in evoking curiosity, attention, and involving the audience in the learning process.

3. A distance lecturer should complete a training course in acting as a part of refresher course.

4. An alliance between two professional: a researching teacher and a professional actor; the first one shall develop the course content, while the actor shall implement the ideas in reality on camera. They both would perform a common task.

\section{Conclusion}

Currently training with telecommunication and Internet technologies represents a sort of symbiosis of media and traditional teaching methods. Content is taken mainly from traditional teaching, while methods and forms of content presentation are derived from television, radio, and cinema.

Considering the distance form of education as an alternative to the long-established traditional form, expanding opportunities for education becoming available to all groups of population, the authors sought to prove that pedagogical success of distance learning could be achieved only if students have a full-scale illusion of direct contact between teacher and student.

While given the fact that the core element of the distance learning is lecture because by no other method but through lectures only a teacher can inspire the students ' interest in the subject, the authors have reviewed acting as part of the teaching practice in distance learning. The examples have been given from the teaching experience in traditional form of learning, and it is demonstrated how the best cases of implementation of pedagogical mastership can be implanted into directing procedure of online lectures.

Currently, many video lectures of all renown universities worldwide are assessible online; however, there are few high-quality ones. Most of the video lectures show a "talking head" that monotonously reads a text, which neither engages anyone nor keeps students focused or interested in the study material. It is a well-known fact that students perceive video lectures well for no longer than 6-10 minutes. Thereafter, their attention decreases as they tend to be distracted by other activities. Few students watch a video 
lecture up to the end. They say, the reason for that is smartphones since one can spend every spare minute to play with a gadget; thus, the students grow a habit of frequent attention switching. A smartphone user needs to change their focus of interest approximately every 10 minutes. The TED lectures, which deliver unique material and expert opinion, are maximum 20 minutes long. Nevertheless, even TED uses special techniques to keep the students engaged: the information is provided "without the fluff" and illustrated by personal experience and vivid images; a lecture is interrupted every five minutes by some suspense or a joke. It is well-understood that one would not need any tricks if a student has high motivation, enough free time and a will of iron to pass the course. But such students have long been a rarity. Under the circumstances, the lecturer's acting skills are particularly essential in creating video lectures, as those skills make it possible to keep the students connected, engaged, and involved throughout the lecture as well as interested in the subject. This may provide an opportunity to eventually improve the quality of distance learning.

\section{References}

1. A.V. Muromceva, I CAN Bulletin, Series Linguistics, 1, 195-198 (2011)

2. A.E. Polichka, Applied informatics 2, 3-11 (2010)

3. O.R. Samartsev, Digital reality. Television of post-industrial era (M: 2009)

4. T. Clark, M.K. Barbour, Online, blended and distance education in schools (Sterling, VA: Stylus Publishers, 2015)

5. C. Cavanaugh, K.J. Gillan, J. Kromrey, M. Hess, R. Blomeyer, The effects of distance education on K-12 student outcomes: A meta-analysis (Naperville, IL: Learning Point Associates, 2006)

6. F. Saba, Distance Education 26, 2, 255-272 (2005) DOI: 10.1080/01587910500168892

7. O. Zawacki-Richter, A. Kourotchkina, Open and Distance Learning 13, 3, 165-184 (2012)

8. I. Komarova, Public education 5, 131-136 (2006)

9. Yu.V. Isaev, Telecommunications and informatization 3, 74-77 (2006)

10. V.P. Bakalov, B.I. Kruk, O.B. Zhuravleva, Distance learning: Concept, Content, Management (M.: Goryachaya liniya-Telecom, 2008)

11. V.V. Muromtcev, Virtual communications in management and education. Proceedings of conference on Theory of active systems (M.: RAS Institute of Control Sciences, 2007)

12. V.V. Muromcev, A. V. Muromceva, The basic properties of virtual communications, The report at the international scientific conference Problem of regional and municipal management, pp. 51-53 (2010)

13. D.A. Ivanchenko, Computer science and education 7, 3-8 (2006)

14. V. Lazarenko, O. Prirodova, V. Nikishina, A. Kuznetsova, Professional education in Russia and abroad 1, 45-52 (2018)

15. M. Loftus, P. Tiernan, S. Cherian, Education and Information Technologies 19(3), 569582 (2014)

16. J. Klein, Education and Information Technologies 18(3), 443-458 (2013)

17. T. Söderström, J. From, J. Lövqvist, A. Törnquist, European Journal of Open, Distance and E-learning 15(1) (2012) 
18. L.B. Mishchenko, Bulletin of practical psychology of education 3, 122-128 (2007)

19. M. Osaka, K. Yaoi, T. Minamoto, N. Osaka, Scientific Reports 3, 1375 (2013)

20. S. Fatahi, Education and Information Technologies 24, 4, 2225-2241 (2019)

21. C. Kim, R. Pekrun, Emotions and motivation in learning and performance. In J. Spector, M. Merrill, J. Elen, M. Bishop (Eds.), Handbook of research on educational communications and technology, 65-75 (New York, NY: Springer, 2014)

22. O. Noroozi, H.J. Pijeira-Díaz, M. Sobocinski, et al, Educ Inf Technol 25, 5499-5547 (2020), https://doi.org/10.1007/s10639-020-10229-w

23. V.N. Glukhikh, N.V. Norina, Education and Information Technologies 21, 1401-1412 (2016), DOI: 10.1007/s10639-015-9390-8 